\title{
Storytelling with Block Coding among College Students at a University in Northern Taiwan
}

\author{
Lih-Juan ChanLin', Te-Lien Chou ${ }^{2}$ \\ ${ }^{1}$ Department of Library and Information Science, Fu Jen Catholic University, Taiwan \\ ${ }^{2}$ Department of English Language and Literature, Fu Jen Catholic University, Taiwan \\ Email: lins1005@mail.fju.edu.tw, 126827@gapp.fju.edu.tw
}

How to cite this paper: ChanLin, L.-J., \& Chou, T.-L. (2022). Storytelling with Block Coding among College Students at a University in Northern Taiwan. Creative Education, 13, 347-365.

https://doi.org/10.4236/ce.2022.132021

Received: January 1, 2022

Accepted: February 11, 2022

Published: February 14, 2022

Copyright $\odot 2022$ by author(s) and Scientific Research Publishing Inc. This work is licensed under the Creative Commons Attribution International License (CC BY 4.0).

http://creativecommons.org/licenses/by/4.0/

\section{Open Access}

\begin{abstract}
In this study, a storytelling approach was adopted in a college elective course, Game-Based Programming. An ADLR model (Analysis, Design, Leveraging, and Refinement) was adopted for story creation in the course. Along with the process of creation, several research questions were specified for further exploration, including: 1) What were the processes by which students analyzed the story project? 2) How did students design their storylines? 3) How did students leverage the use of media in their stories? 4) How did students refine their stories? and 5) How did students react to their achievement from the process? The study employed a qualitative approach to collect multiple research data. Inductive analysis summarized following research findings. To start their story projects, students searched relevant resources, chose a topic, analyzed the features of the platform, and set their own goals to create story content for a specified audience group. Students explored the design features and functions of the 3D story tool, and leveraged the use of media and block codes to present the content and interactions for their stories. They refined their story content by testing and modification to make the interactions tailored to the audience's use. It is suggested that the ADLR process might be adopted for future implementation of digital storytelling.
\end{abstract}

\section{Keywords}

Storytelling, Digital Story, Block Coding, Computation Thinking

\section{Introduction}

Storytelling has been widely applied in communication and practice among diverse professional domains, such as: language acquisition (Lee, 2021), nursing education (Price et al., 2015), the health profession (Moreau et al., 2018), social 
work (La Rose \& Detlor, 2021), journalism curriculum (Bright, 2020), business intelligence (Ramm et al., 2021) and marketing (Gonzalez-Fuentes, Robertson, \& Davis, 2021). In higher education, storytelling is also used as a teaching strategy to invite individuals to use contemporary media to shape and interpret what they perceive and learn by means of designed story content. With the advances of technology applications in 3D design, Augmented Reality (AR), and Virtual Reality (VR), stories can be recreated with different forms of interaction (Krauß et al., 2021). In higher education, students are encouraged to learn the use of advanced tools to create their stories for diverse educational purposes.

In the past, stories were presented with text as the main body. However, evolving technology has changed the medium in which stories are told. Many of these innovative design tools are supported by the $3 \mathrm{D}$ story space together with the use of block codes to direct the scenes (Koushik et al., 2019). With the use of new tools, digital storytelling challenges creators to bring together multimedia elements and scenarios for the design of ambiences within the story context. Digital storytelling challenges student creators to bring together multimedia elements and scenarios for the design of ambiences within the story context. Research on students' use of the new design elements to create interactive stories is needed. It is important to understand the complex decision-making processes, such as analyzing the content/audience and artistic considerations to leveraging the use of media for the final work during the creation processes (Buehring \& Vittachi, 2020; Krauß et al., 2021). Facing challenges in the use of new design tools, it is also worth noting how students adapt to the new form of storytelling to interpret the story content (Jantakoon, Wannapiroon, \& Nilsook, 2019).

Research on students' integration of innovative technology into storytelling will contribute to a deeper understanding of how individuals adopt this new form of digital storytelling to foster creative thinking. In this study, a block coding tool, CoSpaces Edu, was used as a 3D story design space by college students in a "Game-Based Programming" introductory course. Along with the creation process, several research questions were identified, including: 1) What were the processes students used in analyzing the story project? 2) How did students design their storylines? 3) How did students leverage the use of media in their stories? 4) How did students refine their stories? and 5) How did students react to their achievement from the process?

\section{Literature Review}

\subsection{Storytelling in Education}

Storytelling is an important capability for individuals to socialize in their community, at work, and in their social life. Stories can stimulate empathy, critical thinking, and cognitive growth among storytellers and readers, and achieve the intended communication purposes (McCain \& Matkin, 2019; Ochs et al., 1992). Storytelling has been used in different educational settings. Meaningful storytelling interprets intended concepts more successfully via analyzing and relating 
real-life experiences from the audience's perspectives. In educational settings, storytelling is considered an important tool for bridging thinking and experiencing between authors and readers. Via the content of a story, individuals form an identity by projecting themselves into the themes and plots of the story. The internalized and evolving nature of a story encourages individuals to gain a sense of unity and purpose in life (Chow, 2020). In science domains of knowledge learning, storytelling approaches can be used to relate real laboratory experiences to explain concepts and theories. Relevant game activities embedded in the story can be integrated to increase interest the story (Crăciun, Grosseck, \& Bunoiu, 2020). It has been observed that the use of the storytelling approach by university students promoted their perceived usefulness of knowledge and a sense of authentic science learning. Students learned meaningful scientific communications from the storytelling (Olitsky et al., 2020). To improve professional development for nurses, the approach of theme-based storytelling encourages positive learning responses from students, including feelings of joy and warmth, and a sense of clarity and control (Bano et al., 2020). In higher education, storytelling projects can be used as a strategy to encourage collaboration, active learning, and problem-solving capabilities among group members (Ibadango-Galeano et al., 2020). Storytelling capability is omnipresent in our daily lives. Through communication by a story, the audience can understand abstract knowledge concepts, culture, and personal interpretations of the experience content (Di Fuccio et al., 2016).

\subsection{Technology-Mediated Design of Digital Stories}

Traditionally, narrative strategies for storytelling were adopted to engage readers. These strategies include abstract (beginning and summary of the story), orientation (settings of actions temporally and spatially), complicating actions (narration about what happened), result (or resolution), evaluation (unusual aspects of the story), and coda (linking the story with the real world) (Liskin-Gasparro, 1996). Applied to the digital environment, the structures of storytelling can be more complex and interwoven with diverse forms of multimedia and interactive dialogues with the readers. Further analysis of the processes employed by creators might shed light on technology-mediated design of digital stories.

Digital storytelling has revolutionized the way that a story could be created and communicated. Integrating the modern art of story design with the use of various digital media (including texts, images, videos, animations, music, and other media), digital storytelling extends its design space beyond the scope that traditional storytelling could accomplish (Robin, 2016; Robin \& McNeil, 2019). With innovative story design tools, the interface (such as AR/VR) for conveying the content can show the connotation of the story through the use of specific functions and interactions provided by the software and hardware (Rizvic, Okanovic, \& Boskovic, 2020). Digital storytelling becomes a powerful approach for supporting teaching and learning to create personal narratives (Robin, 2016). 
The new technology provides diverse story-worlds, allowing the structure of the entire storyline to combine the characteristics provided by technological tools to create a 3D story world, as well as branches of different scenarios to provide ambiences within the story context (Wood, 2007). In a learning society where the application of science and technology is becoming increasingly popular, anyone can become a creator of a story, for example presenting their own story content in combination with their technological capabilities (animation or film editing), or personal experience, so as to convey special ideas (Felea \& Stanca, 2018). Individuals can convey the connotation of the story they want to tell, use the platforms, and combine the application of various technologies to write their own stories.

\subsection{Digital Storytelling Skills}

In the information society, the digital storytelling capability has become an important form of literacy for diverse learning settings. Applied in higher education, it provides the students with opportunities to utilize different skills and literacies to view or create their own stories in a digital format. The creation of a digital story opens spaces for reflexive and creative praxis which allows creators to express themselves and give voice to intended emotional responses (Nguyen, 2011; Rice et al., 2018). The process also invites the integration of different skills and personal perspectives to produce a meaningful multimedia narrative for the audience (Robin \& McNeil, 2019). Digital storytellers also bring cultural knowledge and life experience, and interact with the audience through their stories (Nguyen, 2011).

In the context of formal education, the potential benefits of digital storytelling have been discussed in literature for its adaptive value of conveying sense-making information (Bietti, Tilston, \& Bangerter, 2019; Di Blas \& Ferrari, 2014; Wu \& Chen, 2020; Nguyen, 2011). By using diverse lines of narrative to present information, ideas, and opinions to the audience, both writers and readers can share the interest and enjoyment of writing and reading (Yiğit, 2020). Integrated with diverse pedagogical contexts, digital storytelling has a great impact on achieving different learning outcomes (including affective, cognitive, conceptual, and academic learning), and fosters collaborative development and re-construction of acquired knowledge (Wu \& Chen, 2020).

Psomos and Kordaki (2018) emphasize the benefits of storytelling activities for participants, including encouraging motivation to learn, providing more personalized learning experiences, cultivating multiple literacies, and providing cooperative learning opportunities (in multi-person creation settings). When involved in storytelling activities, students develop various skills needed in their professional domains (McGee, 2014; Moreau et al., 2018; Price et al., 2015). These skills include communication skills, critical thinking, problem solving, knowledge organization, and creativity (McGee, 2014; Moreau et al., 2018; Price et al., 2015; Yang, Chen, \& Hung, 2020). To express story contents and convey 
personal interpretations, students are encouraged to use various media and tools to design creative themes and content for storytelling. The creation process enables students to learn various skills and accomplish story works through thinking, communication, integration, and organization for needed elements and sets of scenes for the story (Ohler, 2013).

\subsection{Coding for Storytelling}

Coding for storytelling provides a pedagogical approach to encourage students' learning of algorithmic thinking and storytelling skills to achieve story projects goals that are meaningful and relevant to personal needs and interests (Burke \& Kafai, 2010; Whyte, Ainsworth, \& Medwell, 2020). Via coding, the storytelling projects offer students the opportunity to practice algorithmic thinking skills in sequencing, structuring, and clarifying expressions in the story content. The process also encourages narrative and reflective thinking skills from the creation of the story (Burke \& Kafai, 2010). With the features embedded in the new tools for storytelling, students are able to grasp programming concepts using different cognitive learning styles, including visual, auditory, kinesthetic, reading and writing to improve their understanding and skills in coding (Mbunge, Fashoto, \& Olaomi, 2021). Students are encouraged to explore the innovative approach of story creation. Diversified 3D animation and tangible technology (such as AR and VR, embedded in many of these design platforms (for example: Scratch, Blockly, StoryBlock, CoSpaces Edu) are available. These types of software provide a 3D interface that allows students to code with the objects, scenes, and characters, in their applications (Koushik, Guinness, \& Kane, 2019; Pasternak, Fenichel, \& Marshall, 2017). Students can upload the resources or elements provided by the system or use self-made media (3D animation objects, still images, 360 scene images, sounds, text, etc.) in their story design. Differing from traditional programming learning, the programming languages embedded in these systems are object-oriented and can be easily adopted for command execution. For programming beginners, it is an interesting coding exploration (Fraser, 2015). For example, recent advances of CoSpaces Edu enable users to practice algorithms and computation thinking by manipulating objects and characters via block-based visual programming language and editors (Jane, Medlock-Walton, \& Tissenbaum, 2017).

In CoSpaces Edu, diverse 3D design scenes are provided in the system. Students can incorporate different objects and characters and learn block-based programming to manipulate the objects and characters in the scenes. Used in the story design, various story interfaces and interactive elements can be applied, such as AR or VR interaction, block editors for interactive response, camera movement, and animation of the $3 \mathrm{D}$ objects. For beginners, the use of visual programming editors is more intuitive to work with. Students learn to code by building the blocks with embedded scripts to execute commands (Nguyen, Jung, \& Dang, 2020; Zhang \& Biswas, 2017). Coding with this new type of tool, stu- 
dents are offered new opportunities to explore programming. It is also worth researching how students adapt and apply the new tools to design their own stories for their audience.

\section{Methodology}

\section{Background Settings}

In a university in northern Taiwan, an introductory elected semester-course, Game-Based Programming, was offered to provide novice students with introductory programming experience. From the course, a storytelling approach using CoSpaces Edu was integrated in two basic programming classes: Game-Based Programming. The study employed a qualitative approach to collect multiple research data. Convenience sampling was used to collect samples conveniently accessed from the course. Students enrolled in the course were the research subjects in this study. These students were all novices, majoring in English Literature and Information Innovation and Digital Life. A storytelling project was assigned to the courses to provide students with an innovative design experience. Students were encouraged to apply critical logical thinking and problem-solving skills from learning programming with the authoring tool.

Using CoSpaces Edu, students created scenes from scratch or used $360^{\circ}$ photos as the story background for adding elements. By dragging and dropping objects and characters from the library of 3D models, the virtual world was created (Figure 1). Textual narrations and dialogs among characters were inserted with a message box or attribute settings of the characters. All of the motion plays on the screen were executed by the command in block codes. From the tool, students were also offered new exploratory opportunities to integrate AR/VR modes or Merge Cube AR simulations for their designs. The built-in 3D physics engine allowed students to use the block codes to activate the real-world physics properties to make the objects react just like they would in real life. During their coding process, students switched between "block code" and "play" modes to work with their stories. For those stories designed with Merge Cube, the cubes were used as a trigger for merging the physical cube-interactions with virtual scenes in the stories. For example, in Figure 1 (on the right), the scene for the

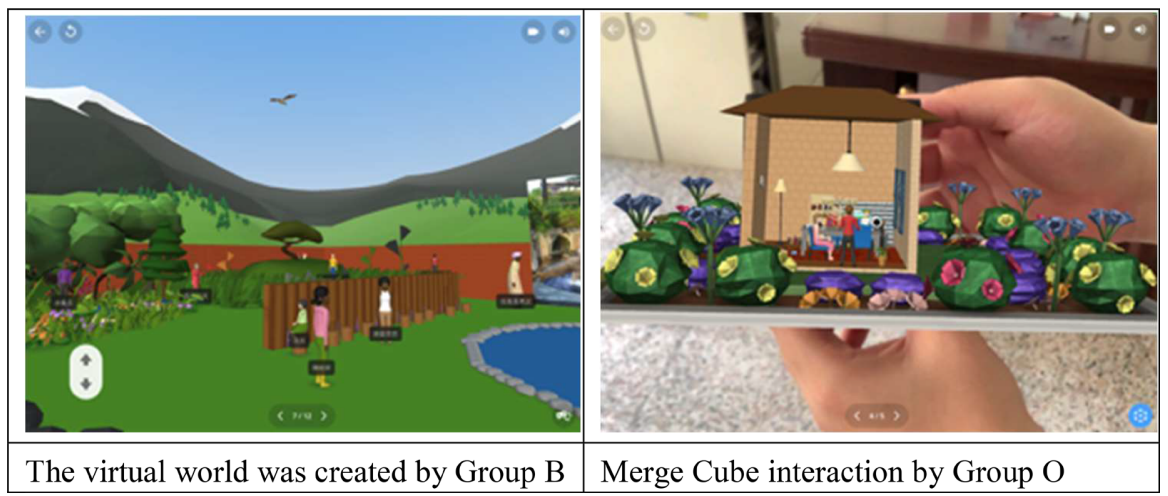

Figure 1. Construction of story scenes with $3 \mathrm{D}$ objects and characters 
interaction with a Merge Cube was created. As the cube was scanned by the camera lens of the mobile device, the story scene was overlaid onto the cube. The cube could be rotated to a different angle to watch the story play in a 3D story space. Designing for Merge Cube interaction, students needed to use the cube to create different types of story scenes for merging physical and virtual interaction for viewers.

In the course, the model for approaching the storytelling project was adapted partially from the guidelines suggested by Nguyen (2011), Robin and McNeil's (2019) ADDIE, and Gaudenzi's (2019) WHAT IF IT models. The guiding procedures were adjusted to focus on the development process. Tasks involved in the story included: analysis, design, leveraging, and refinement (test/revision) using the acronym, ADLR (Figure 2). The tasks involved in the ADLR are listed in Figure 2, starting from analyzing the audience and setting the objectives, designing storylines, leveraging the use of media elements, and refining the story content through testing and revision.

In the course, the skills needed to accomplish the project objectives were taught, including the use of the CoSpaces Edu platform, introduction to the basic components of a story, and diverse approaches (examples) to design stories. Guided by the ADLR model, students were encouraged to conceive their digital stories as a transformative journey that conveyed information, emotion, and knowledge through block coding. To meet the project requirement the story projects should use at least three of the following types of programming syntax: sequential, loop, parallel, event, condition, variables, and list.

In the ADLR approach, learning supports were provided in different stages of

\begin{tabular}{|c|c|c|c|}
\hline & Tasks & The use of tools & Learning support \\
\hline & $\begin{array}{l}\text { Analysis of audience } \\
\text { Objective of the story } \\
\text { Themes of the story } \\
\text { Analysis of the story } \\
\text { content }\end{array}$ & $\begin{array}{l}\text { Analyzing the } \\
\text { features and functions } \\
\text { of the platform } \\
\text { Analyzing the media } \\
\text { resources for use }\end{array}$ & $\begin{array}{l}\text { Suggestions about the } \\
\text { topic and target } \\
\text { audience Practice for } \\
\text { computation thinking } \\
\text { Story examples }\end{array}$ \\
\hline & $\begin{array}{l}\text { Design of storyline } \\
\text { Story flowchart } \\
\text { Planning of } \\
\text { characters, scenes, } \\
\text { and interactions }\end{array}$ & $\begin{array}{l}\text { Storyboarding } \\
\text { Organizing and } \\
\text { structuring the story } \\
\text { content } \\
\text { Learning functions of } \\
\text { the coding tool }\end{array}$ & $\begin{array}{l}\text { Design ideas } \\
\text { Design suggestions } \\
\text { Guidance for different } \\
\text { function blocks } \\
\text { Coding guidance } \\
\text { Examples from Gallery }\end{array}$ \\
\hline & $\begin{array}{l}\text { Integration of scenes, } \\
\text { characters and media } \\
\text { objects with the story } \\
\text { content }\end{array}$ & $\begin{array}{l}\text { Coding with media } \\
\text { Structuring block } \\
\text { codes for objects and } \\
\text { scenes } \\
\text { Switching modes for } \\
\text { playing and coding } \\
\end{array}$ & $\begin{array}{l}\text { Tips and reminding } \\
\text { Guidance for debugging } \\
\text { and problem-solving } \\
\text { Reorganization for } \\
\text { efficient coding }\end{array}$ \\
\hline & $\begin{array}{l}\text { Testing and } \\
\text { modifying } \\
\text { Refining and } \\
\text { polishing the story } \\
\text { content }\end{array}$ & $\begin{array}{l}\text { Repeated debugging } \\
\text { and revision } \\
\text { Restructuring and } \\
\text { modifying }\end{array}$ & $\begin{array}{l}\text { Step-by-step testing } \\
\text { Help with debugging } \\
\text { Commenting on } \\
\text { improvement of the } \\
\text { story works. }\end{array}$ \\
\hline
\end{tabular}

Figure 2. ADLR approach revised from ADDIE and WHAT IF IT models. 
planning story works. These suggestions covered setting objectives for the story, design tips, available resources, debugging of story works, and efficient coding for the design of interactions (Figure 1). Along with the process of working on the story projects, multiple research data were gathered in different stages (Table 1).

Project interviews were carried out together with students' mid-term and end-of-term oral presentations on a group basis. The interview guide used to guide students' responses is listed in Table 1. Each project interview lasted for 10 - 15 minutes. The questions were responded to, recorded, and transcribed for further analysis. Inductive analysis was used to merge different data sources (including students' story works, mid-and end-of-term project interviews, and observations from the class) to summarize the research findings.

\section{Findings}

Students were encouraged to integrate the block coding tool to create their own stories. The processes involved in the approach included the planning for the design and learning to use the storytelling platform, CoSpaces. The ADRL model was used to guide students' process for the storytelling project. Students' storytelling started with analyzing the task, setting the target audience, and designing storylines, followed by leveraging the use of media and refining the project works. The processes involved in storytelling were summarized based on Tasks and Actions in different categories (Figure 3): Analyzing the story task,

Table 1. Matching research questions with the interview guide at different stages.

\begin{tabular}{|c|c|c|c|}
\hline Research question & Project inter & view (mid-term/end-term) & In-depth interview (end of course) \\
\hline $\begin{array}{l}\text { (1) What were the processes } \\
\text { involved by students in } \\
\text { analyzing the story } \\
\text { project? }\end{array}$ & $\begin{array}{l}\text { Mid-term } \\
\text { project } \\
\text { interview }\end{array}$ & $\begin{array}{l}\text { Who was your audience for the story? } \\
\text { What were the objectives of the story? }\end{array}$ & $\begin{array}{l}\text { How did you negotiate with your group } \\
\text { members to decide on a topic for your story? }\end{array}$ \\
\hline $\begin{array}{l}\text { (2) How did students design } \\
\text { their storylines? }\end{array}$ & & $\begin{array}{l}\text { What was the design you used to } \\
\text { achieve the objectives of the story? } \\
\text { How did you use your flowchart for } \\
\text { telling the story? }\end{array}$ & $\begin{array}{l}\text { What was the significant design in your } \\
\text { story? } \\
\text { How did you plan and allocate } \\
\text { responsibilities in your team? }\end{array}$ \\
\hline $\begin{array}{l}\text { (3) How did students } \\
\text { leverage the use of media } \\
\text { in their stories? }\end{array}$ & $\begin{array}{l}\text { Final project } \\
\text { interview }\end{array}$ & $\begin{array}{l}\text { How did you accomplish your project } \\
\text { tasks? } \\
\text { What were the problems you } \\
\text { experienced in the creation process? } \\
\text { How did you solve your problems? }\end{array}$ & $\begin{array}{l}\text { How did you negotiate with your team } \\
\text { members at any key point for } \\
\text { decision-making? } \\
\text { How did you overcome your obstacles? }\end{array}$ \\
\hline $\begin{array}{l}\text { (4) How did students refine } \\
\text { their stories? }\end{array}$ & & $\begin{array}{l}\text { How did you refine your story during } \\
\text { the process of creation? } \\
\text { How did you adjust your design to } \\
\text { make it more manageable? }\end{array}$ & $\begin{array}{l}\text { How did you modify your story to improve } \\
\text { the quality of your story work? } \\
\text { How did you monitor your progress on time? }\end{array}$ \\
\hline $\begin{array}{l}\text { (5) How did students react } \\
\text { toward their } \\
\text { achievement? }\end{array}$ & & $\begin{array}{l}\text { How did you experience the process of } \\
\text { storytelling? }\end{array}$ & $\begin{array}{l}\text { What did you learn from } \\
\text { the whole process? }\end{array}$ \\
\hline
\end{tabular}




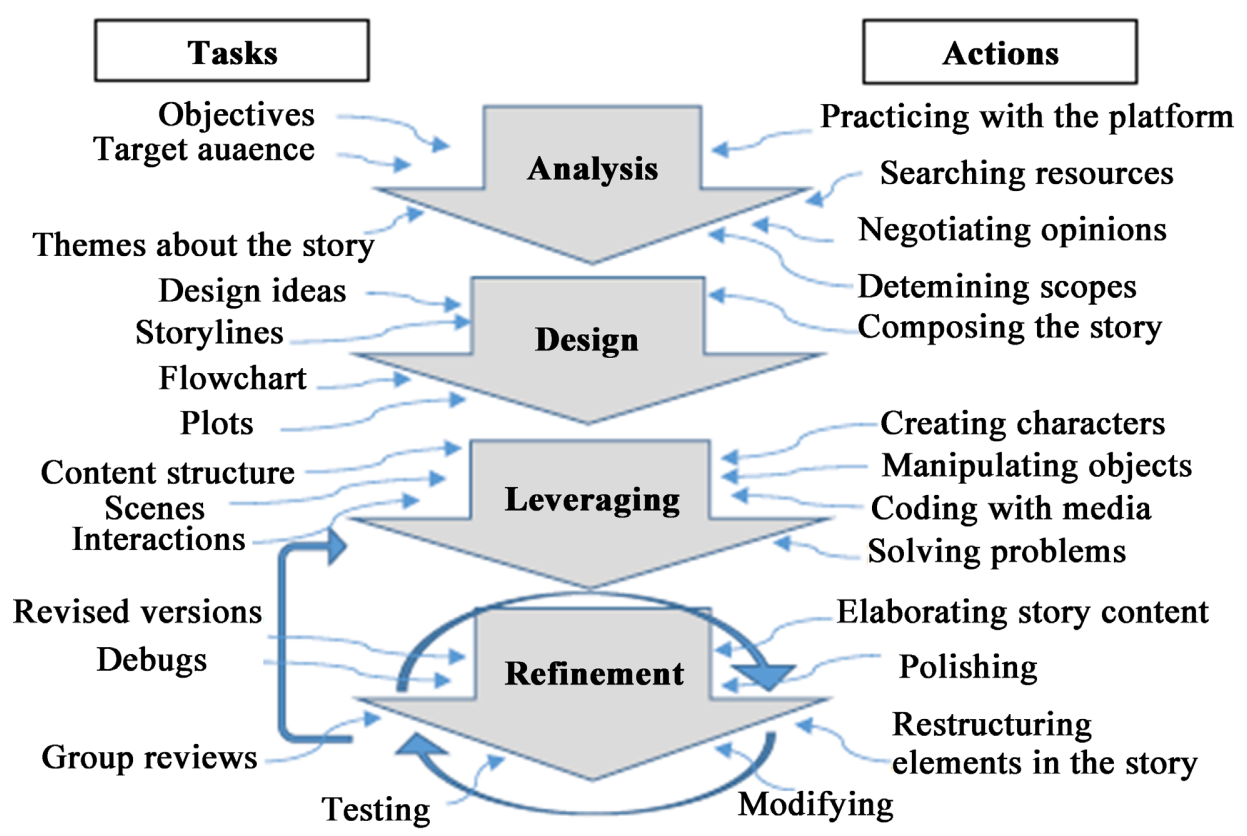

Figure 3. Themes evolved from research data.

Designing the storyline and flowchart, Leveraging the use of media for the story, and Refinement.

\subsection{Analyzing the Story Task}

To start with the story task, most groups used the story content they were interested in, and set the target audience that they were more familiar with. Relevant resources were searched for and analyzed by the groups for the design of their story themes. Students chose the topics based on their own interest. Many groups revised the existing stories to make their own. They searched and used diverse resources (from websites, YouTube and the galleries of CoSpaces) for the design of their own storyline. Some groups also used the Covid-19 pandemic and inquired about information as the story background to make the story informative (Groups A, E, H and I). Students' story projects were categorized into different subject areas: Artists and Artworks, Culture and Festivals, Environmental Protection, Life and Health Knowledge, Tours and Exploration, and Psychotherapy (Table 2). Among these topics, culture and festival-related content was the most commonly chosen as story topics due to the approaching holiday season.

"In order to help people to appreciate Jewish culture, a story related to Hanukkah traditions will be introduced by our team. The audience would also enjoy playing with a dreidel in the story." (Group O).

To start a story, members within each group might have a disagreement about the choice of story content and be disoriented about managing their time and effort. They had to negotiate diverse opinions, and determine the scope that they wanted to cover in their story. 
Table 2. Topics of stories.

\begin{tabular}{cc}
\hline Category of story topics & Group number \\
\hline Artists and Artwork & C, P, Q, U \\
Culture \& Festivals & N, R, S, T \\
Environmental Protection & D, F, L, K \\
Life and Health Knowledge & A, H, I, J \\
Tours and Exploration & G, E, M \\
Psychotherapy & B \\
\hline
\end{tabular}

"I shared with my team member the idea I had in mind for our story. My partner also had her own thoughts to extend the content of the story.... However, it would be too complex if we wanted to cover too much in our story. We had to narrow it down to the extent that we could handle." (Group L).

\subsection{Designing the Storyline and Flowchart}

To design the storyline for their stories, students were encouraged to think and work creatively to plan for the scenes needed for their stories. They also wrote down the narrations to describe the story background, characteristics, and themes to compose the story. For example, Group O explained the history and origin of the dreidel (a four-sided spinning top played with during the Jewish holiday of Hanukkah).

"The family members gathered in the living room. Starting to play with the dreidel, the father turned each side of the spinning-top to the family members. The boy explained the rules of the game, and invited everyone to join in..." (Group O).

To sequence the story and help algorithmic thinking in coding with CoSpaces, students designed flowcharts as a diagrammatic representation of logical steps for their stories. In the beginning, it was observed that many groups did not use appropriate symbols to represent the logical steps in planning their story content. After guided practices, students were able to use the programming flowcharts to represent their algorithm thinking.

\subsection{Leveraging the Use of Media for the Story}

Working with the CoSpaces 3D platform, students created textual descriptions of the scenes of their stories. They also pulled together the objects and materials (such as walls, plants, stones, bricks, etc.) from the 3D database or external websites to construct the scene components (such as gardens, forests, and houses). They learned the basics of manipulation of a $3 \mathrm{D}$ object including scaling, rotation, and moving by controlling the $\mathrm{x}, \mathrm{y}$, and $\mathrm{z}$ axes. The experience was novel to most students. They learned to manipulate the $3 \mathrm{D}$ objects by labeling the objects, 
dragging the block codes, and setting the objects for execution. Together with the constructed scenes, students learned to elaborate verbally on the visual components they had created. The expression and actions of specific characters also iterated the purpose of the story. For example, in the story, Guardians of Our Ocean, Group F made the story character say: "Cheap and handy plastic bags make human life easier, but pollute our planet at the same time. Plastic pollution influences our oceans. The marine animals' lives are threatened by the plastic waste."

From their story projects, students learned to use the block syntax to execute the motions and animations and direct the scenes. Frequent discussion was used to cope with the problems encountered in story creation. Solving the problems entailed students practicing with needed skills, constructing conceptual understanding, and discovering the alternatives to cope with their obstacles and unsatisfactory parts in their works. The instructor also helped students with hints and guidance to ensure that no important steps were overlooked.

"I want to create a scene about a running horse approaching a junction." (Group B)

"You can create a junction by pulling the objects here (talking to the screen), and changing the shape and texture. Pull a character into the scene, and make the camera attach to his head. Lock the house and other objects. When the character moves, the camera and scene will move." (the Instructor)

"We want the audience to have a panoramic view of the story space" (Group L)

"You need to add a new camera and a new CoBlock. Name the camera Camera 1 and use the Transform function to turn Camera 1 clockwise by $345^{\circ}$ in a given time" (the Instructor).

"In the second scene, you might want to give a little hint, otherwise the player would not know what to do." (the Instructor)

Telling a story about specific cultural traditions invited students to explore diverse design details and crucial elements in the story. It also conveyed important personal reflections and embedded value. Through the design elements, students interpreted the story with intended purpose by overcoming the obstacles. For example, to tell a story about Judith, a Jewish heroine, students of Group U encountered difficulties getting enough resources for story characters, objects, and stage backgrounds. To cope with the problems, they searched for and downloaded Renaissance artwork from the Internet and modified these artworks for use as story elements. "Fair use doctrine" was claimed and followed to meet the learning requirements. In the story of Return of Judith, Group U modified the artwork elements (by the artist, Sandro Bethulia) for use in the story.

"From the artwork of the story, we wanted to emphasize the audacity and 
courage of Judith. We searched for resources from Renaissance paintings. We adapted and modified the elements to use with block codes." "For example, in the scene of Holofernes' death: After Holofernes was killed by Judith, we changed Holofernes' opacity to $50 \%$ (as a ghostly figure). The reactions of Holofernes run "parallel" with those of Judith, so that action-reaction paired up" (Group U)

\subsection{Refinement}

To work with the block coding, students frequently switched between the block codes and the story scenes for checking the actions and events occurring in their stories. The stories were tested and modified frequently. Many students started with linear sequences of manipulating the scenes and actions. Dynamic processes of adding, transforming, changing, reverting, rearranging, and modifying were observed. After becoming more familiar with the operation of the tools, they came up with new ideas about branches and looping structures, and strived to try out and revise to deepen the content of the story. They were also more confident in facing the challenge of efficient coding, for example, the decision to use parallel execution of concurrent events in the story scenes. Deletion of decoration elements and the use of multiple loops for repeated actions were also adapted by students for efficient coding and loading time.

"Instead of executing a long line of codes, we re-organized the block codes for repeated events. We also deleted some decoration elements in the scene to speed up the loading time." (Group O).

In Group L's story, the interactive story "Go Green" was designed based on different age groups. The group started with the first age group, and then added multiple loops into the block codes for diverse interactive points in the story. The group members challenged themselves with higher levels of block codes to accomplish their story project (Group L).

"We did not give up the idea about setting different story content for different age groups. Although we encountered barriers in structuring the branches and loops, we finally accomplished the task as planned. The coding for the design was more complicated, we experienced extensive and tedious trial-and-error, but finally we made it."

In Group D’s story, “Forest Green”, students spent much time adjusting the spinning movement of the houses as the earth rotated simultaneously. They were guided by the instructor and edited the scripts to coordinate the motions among objects on the screen. After revising the screenplay over and over again, the group was able to present a fascinating opening scene for the story. (Group D)

"For the first scene, we put the houses on the track to rotate. To coordinate with the earth's rotation, the houses needed to turn to the right side up as they moved. "We tried to adjust the time for rotation, and replace it with 
another track of movement for the screenplay." (Group D) "I encourage you to try by editing the scripts and parameters little by little... You need to check and see the difference from the scene". (Group D and Instructor)

\subsection{Achievement}

Analysis of the 17 groups' story projects in the two classes showed that they all achieved their project objectives. Most projects were created with diverse issues related to concurrent news and events, such as health knowledge, environmental conservation, artists and artworks, national parks, Christmas, and Hanukkah. In their stories, game-like activities were used to encourage interactions with readers.

From their creation process, learning the use of the $3 \mathrm{D}$ platform was a novel and exciting experience for most students. They assembled the objects needed for their stories, manipulated the characters in the 3D story space, and explored the use of CoSpaces block codes to work with the story scenes. Engaged in handling the visual and audio elements in the story, the students became film-directors who controlled the dramatic aspects of the story. They learned to visualize the screenplay while using the block codes for programming. From their learning reflections, one student in Group L mentioned that she was most impressed by the use of parallel functions in the block codes to visualize the concurrent actions among objects in the scene. The students in Group $U$ most enjoyed the interactive design they experienced from their design.

"The parallel execution of simultaneous motion capability in the block codes allowed me to create more than one action at the same time." (Group L)

"I enjoyed making the character talk. In the $1^{\text {st }}$ scene, I made the artist, Botticelli speak to the audience by eliciting responses via the interactive message box. The design made the story interactive and interesting." (Group U)

From exploration of the design of the screenplay, students experienced trial-and-error to find out a better way to solve the problems encountered in the storytelling process. As they were more involved in the design themes of the $3 \mathrm{D}$ story space, students also needed to allocate their time and effort to meet the project deadline. Some changed their plans accordingly to make the task more manageable. Some modified their story flow to make their interactions tailored to the audience's use habits. For example: Group E narrowed down the story content, and focused on travelling tips for specific areas. Group $\mathrm{N}$ re-arranged sequence flow of scenes to make the interactions more effective. Group O deleted some decorated objects to speed up the loading time of the story. Group N and $\mathrm{R}$ revised the scene to create the ambience of the setting which fit into the story background. From the modification and refinement of the story, students experienced the importance of making their design tune into the audience's use and needs.

"Originally, there was no transmission between Scene 2 and Scene 3. In the new version of the story, the audience can follow the given instruction to 
move on to the next scene by clicking on the pointer" (Group P).

Overall, students enjoyed the use of the $3 \mathrm{D}$ platform to create their stories. The story-creation process was a constructive learning process among students. They set their own goal to tell a story to a specific audience group. They also explored the design features provided by the design tool and tried with the block codes to direct the scenes for their stories.

"It was an interesting and satisfactory experience to share with the audience our story via CoSpaces (Group U). The 3D story space allowed us to create and share dynamic design elements and concurrent events in the scenes. The story was told in different narrative forms. In the beginning of the planning process, we had our own idea about how we were going to tell the story. To achieve our goal, we had to explore the design features embedded in the tool. Although there was too much to learn from the system, we only picked what was needed and constructed the scenes and elements for our own story." (Group U)

"It took us much time to synthesize dynamic scenes and rearrange the scene flows across time and space in the story. We enjoyed the adventure we were exploring in the process of story creation. Although there were problems encountered, the teacher gave us guidance on the solutions. I have to think thoroughly for rearrangement of the scene flows for the interactions we designed for the story.” (Group L).

\section{Discussion}

In this study, ADLR model was used to analyze students' learning process of creating interactive stories. From the process of creation of digital interactive stories, students learned block coding skills via the CoSpaces platform. They also learned the basic components of a story, and diverse approaches (examples) to design stories. Additional guidance support including suggestions for the processes involved in different stages (analysis, design, leveraging, and refinement) of story creation were provided.

Applying the new tool to work with their story projects, students created their 3D story works, a new form of art, combining diverse forms of media, setting physical movement of the objects via the $3 \mathrm{D}$ platform and block codes. As emphasized by related literature, the use of new interfaces modulates the process of content creation when the meanings and expressions of the digital works are constructed in the new design space (Liu, 2020; Sintonen, 2020). In line with this notion, findings of our research indicated that the students use the $3 \mathrm{D}$ block codes as their new design space. They were encouraged to think creatively by the change of creation means and expression to broaden appreciation and deepen visual experiences in the author-viewer interactions. Observed from their creation process, students experimented and played with the design tools to achieve their project goals. They also experienced a dynamic process of adding, trans- 
forming, changing, reverting, rearranging, and modifying their works in many ways. The creation process was constructive, self-expression, self-reflective, and self-learning, and the self-designed content helped students to be engaged in the creation process and achieve their project goal.

From the past efforts in teaching programming languages, students with limited coding skills might be frustrated with general programming applications for creative design. The use of newly developed tools extends many different domains of storytelling applications (Jung, Nguyen, \& Lee, 2021). In our study, a web-based development tool with embedded VR/AR features, as well as the usability of 3D objects and panoramas was employed by students to create stories for a mobile audience. Students were offered new design opportunities to create stories with diverse mobile interactions. The visual programming experiences for the execution of intuitive "drag and drop" block codes also allow general students without advanced programming training to practice logical and computation skills by utilizing the visual programming tool.

As novice programmers, students learned the basics of logic and computation thinking. In the beginning, many of them failed to draw an appropriate flowchart to represent the step-by-step execution of story scenes. After exploration with the block codes, students obtained conceptual understanding of algorithm thinking through visualizing the execution of the codes they constructed for playing their story content over and over again.

From the storytelling approach adopted in the study, students were active creators and directors of their own stories, rather than passive users applying new technology. Through the use of media and visual elements to narrate the story content, personal interpretations and meanings were conveyed. Storytelling is highlighted as a powerful pedagogical tool that opens up possibilities for students' engagement in interpretative and relational learning, and opportunities to examine the narratives that are told (Astiz, 2020; Lewin, 2011). In our study, we observed that students used the design elements and the connotation of the stories to convey personal experiences and emotional feelings to interact with their audience. They also refined their designs to make the final works more usable. From the modification and refinement of the story, students experienced the importance of making their design tailored to the audience's use.

\section{Conclusion}

In this study, students' learning process in creating interactive stories was studied. Guided by the ADLR model, the storytelling employed a participatory approach to encourage students' learning in game-based programming. From the process of creating a digital interactive story, students learned the block coding skills via the CoSpaces platform. The final products of students' stories were diversified in content and forms of interactions (including the use of Merge Cube). In addition to achieving their final goals, students also learned from the process of accomplishing different tasks (analysis, design, leveraging, and refinement) in 
story creation. With the use of the 3D platform for creating digital stories, students were engaged in design and analysis thinking skills. As they became more involved with the platform, they were able to deepen their algorithm thinking skills and leverage the use of design elements for constant refinement of their story content. More in-depth change processes in creative thinking are valuable for the whole learning process.

This study might have a limitation in that only an exploratory case was observed. With an emphasis on qualitative analysis of the process in storytelling via the use of the block coding tool by novice programmers, the findings of the study might be limited in terms of generalizing the findings to other settings. Further analysis using different samples and extending the scope and research approach might render more persuasive research findings in the future. Since more new digital tools have made constructing visual arguments more applicable to non-experts to produce fascinating digital stories, a potential thinking process in analysis and design is needed to guide authors and creators to leverage the use of media and refine their story content to ensure their stories achieve their intended purposes. It is also hoped that the ADRL model might be applied to other contexts where digital story creators seek guidance for their design approach.

\section{Acknowledgements}

We very much appreciate the support from Fu Jen Catholic University and the story project works shared by the class students.

\section{Conflicts of Interest}

The authors declare no conflicts of interest regarding the publication of this paper.

\section{References}

Astiz, M. F. (2020). Storytelling in the Higher Education Classroom: Why It Matters. College Teaching, 68, 187-188. https://doi.org/10.1080/87567555.2020.1785382

Bano, N., de Beer, J., Omer, T., \& Rawas, H. (2020). Theme-Based Storytelling in Teaching Pharmacology to Postgraduate Nursing Students. Cogent Education, 7, Article ID: 1770922. https://doi.org/10.1080/2331186X.2020.1770922

Bietti, L. M., Tilston, O., \& Bangerter, A. (2019). Storytelling as Adaptive Collective Sensemaking. Topics in Cognitive Science, 11, 710-732. https://doi.org/10.1111/tops.12358

Bright, A. (2020). Journalism Curriculum Frameworks Shift toward Skills, Interdisciplinarity. Teaching Journalism \& Mass Communication, 10, 1-7. https://aejmc.us/spig/wp-content/uploads/sites/9/2020/06/TJMC-10.1-Bright-Journalis m-Curriculum-Frameworks.pdf

Buehring, J., \& Vittachi, N. (2020). Transmedia Storytelling: Addressing Futures Communication Challenges with Video Animation. Journal of Futures Studies, 25, 65-78.

Burke, Q., \& Kafai, Y. B. (2010). Programming \& Storytelling: Opportunities for Learning about Coding \& Composition. In N. Pares \& M. Oliver (Eds.), Proceedings of the 9th International Conference on Interaction Design and Children (pp. 348-351). Associa- 
tion for Computing Machinery. https://doi.org/10.1145/1810543.1810611

Chow, E. (2020). Use of Storytelling to Enhance the Teaching and Learning of ss3280/ ss5212 Human Behaviour and Social Environment/Diversity.

Crăciun, D., Grosseck, G., \& Bunoiu, M. (2020). Game-Based Storytelling in Non-Formal Romanian Science Education. AIP Conference Proceedings, 2218, Article ID: 060009. https://doi.org/10.1063/5.0005845

Di Blas, N., \& Ferrari, L. (2014). Digital Storytelling at School: What Kind of Educational Benefits? International Journal of Arts and Technology, 7, 38-54. https://doi.org/10.1504/IJART.2014.058942

Di Fuccio, R., Ponticorvo, M., Ferrara, F., \& Miglino, O. (2016). Digital and Multisensory Storytelling: Narration with Smell, Taste and Touch. In K. Verbert, M. Sharples, \& T. Klobucar (Eds.), European Conference on Technology Enhanced Learning (pp. 509-512). Cham: Springer. https://doi.org/10.1007/978-3-319-45153-4 51

Felea, C., \& Stanca, L. (2018). Digital Storytelling for Teaching Romanian for Academic Purposes-An Optimal Method for Developing Employability Skills? The International Scientific Conference eLearning and Software for Education, 4, 163-170.

Fraser, N. (2015). Ten Things We've Learned from Blockly. In F. Turbak, D. Bau, J. Gray, C. Kelleher, \& J. Sheldon (Eds.), 2015 IEEE Blocks and Beyond Workshop (Blocks and Beyond) (pp. 49-50). IEEE. https://doi.org/10.1109/BLOCKS.2015.7369000

Gaudenzi, S. (2019). The WHAT IF IT Process: Moving from Story-Telling to Story-Experiencing. Alphaville: Journal of Film and Screen Media, No. 17, 111-127. https://doi.org/10.33178/alpha.17.07

Gonzalez-Fuentes, M., Robertson, K. R., \& Davis, J. C. (2021). Creativity as a Reflective Learning Exercise: Informing Strategic Marketing Decisions through Digital Storytelling. Marketing Education Review, 31, 138-146. https://doi.org/10.1080/10528008.2021.1907201

Ibadango-Galeano, E., Vargas-Chagna, L., Varela, M. G., Velez-Meza, M., \& Placencia-Enriquez, E. (2021). Storytelling Digital: Experience and Technology in Designs of Tele-Collaborative Projects in Higher Education. In M. Botto-Tobar, S. M. Leon, O. Camacho, D. Chavez, P. Torres-Carrion, \& M. Z. Vizuete (Eds.), Applied Technologies: Second International Conference, ICAT 2020 Proceedings (Vol. 1388, pp. 151-163). Springer Nature. https://doi.org/10.1007/978-3-030-71503-8 12

Jane, I.M., Medlock-Walton, P., \& Tissenbaum, M. (2017). App Inventor VR Editor for Computational Thinking. In S. C. Kong, J. Sheldon, \& K. Y. Li (Eds.), Conference Proceedings of International Conference on Computational Thinking Education 2017 (pp. 160-163). Hong Kong: The Education University of Hong Kong.

https://documents.pub/document/app-inventor-vr-editor-for-computational-thinkinginventor-vr-editor-for-computational.html

Jantakoon, T., Wannapiroon, P., \& Nilsook, P. (2019). Virtual Immersive Learning Environments (VILES) Based on Digital Storytelling to Enhance Deeper Learning for Undergraduate Students. Higher Education Studies, 9, 144-150.

Jung, K., Nguyen, V. T., \& Lee, J. (2021). BlocklyXR: An Interactive Extended Reality Toolkit for Digital Storytelling. Applied Sciences, 11, Article No. 1073. https://doi.org/10.3390/app11031073

Koushik, V., Guinness, D., \& Kane, S. K. (2019). StoryBlocks: A Tangible Programming Game to Create Accessible Audio Stories. In Proceedings of the 2019 CHI Conference on Human Factors in Computing Systems (pp. 1-12). Association for Computing Machinery. https://doi.org/10.1145/3290605.3300722 
Krauß, V., Boden, A., Oppermann, L., \& Reiners, R. (2021). Current Practices, Challenges, and Design Implications for Collaborative AR/VR Application Development. In Proceedings of the 2021 CHI Conference on Human Factors in Computing Systems (pp. 1-15). Association for Computing Machinery. https://doi.org/10.1145/3411764.3445335

La Rose, T., \& Detlor, B. (2021). Social Work Digital Storytelling Project: Digital Literacy, Digital Storytelling, and the Makerspace. Research on Social Work Practice, 31, 599-609. https://doi.org/10.1177/1049731521992427

Lee, S. Y. (2021). Storytelling and Sustained Silent Reading in Foreign Language Acquisition: Evidence from Taiwan. In IASL Annual Conference Proceedings. World Class Learning and Literacy through School Libraries. https://doi.org/10.29173/iasl7956

Lewin, T. (2011). Digital Storytelling. Participatory Learning and Action, 63, 54-62. https://insightshare.org/wp-content/uploads/2017/06/InsightShare-global-network-ofcommunity-owned-video-hubs-S.MunizInsightShare.pdf\#page $=56$

Liskin-Gasparro, J. E. (1996). Narrative Strategies: A Case Study of Developing Storytelling Skills by a Learner of Spanish. The Modern Language Journal, 80, 271-286.

Liu, X. L. (2020). Artistic Reflection on Artificial Intelligence Digital Painting. Journal of Physics: Conference Series, 1648, Article ID: 032125. https://doi.org/10.1088/1742-6596/1648/3/032125

Mbunge, E., Fashoto, S., \& Olaomi, J. (2021). Covid-19 and Online Learning: Factors Influencing Students' Academic Performance in First-Year Computer Programming Courses in Higher Education. SSRN. https://doi.org/10.2139/ssrn.3757988

McCain, K. D., \& Matkin, G. S. (2019). Emerging Adults Leadership Identity Development through Family Storytelling: A Narrative Approach. Journal of Leadership Education, 18, 159-169.

McGee, P. (2014). The Instructional Value of Digital Storytelling: Higher Education, Professional, and Adult Learning Settings. New York: Routledge. https://doi.org/10.4324/9780203066140

Moreau, K. A., Eady, K., Sikora, L., \& Horsley, T. (2018). Digital Storytelling in Health Professions Education: A Systematic Review. BMC Medical Education, 18, Article No. 208. https://doi.org/10.1186/s12909-018-1320-1

Nguyen, A. (2011). Negotiations and Challenges in Creating a Digital Story: The Experience of Graduate Students. Doctoral Dissertation, University of Houston. https://uh-ir.tdl.org/handle/10657/276

Nguyen, V. T., Jung, K., \& Dang, T. (2020). BlocklyAR: A Visual Programming Interface for Creating Augmented Reality Experiences. Electronics, 9, Article No. 1205. https://doi.org/10.3390/electronics9081205

Ochs, E., Taylor, C., Rudolph, D., \& Smith, R. (1992). Storytelling as a Theory-Building Activity. Discourse Processes, 15, 37-72. https://doi.org/10.1080/01638539209544801

Ohler, J. B. (2013). Digital Storytelling in the Classroom: New Media Pathways to Literacy, Learning, and Creativity. Thousand Oaks: Corwin Press. https://doi.org/10.4135/9781452277479

Olitsky, S., Becker, E. A., Jayo, I., Vinogradov, P., \& Montcalmo, J. (2020). Constructing "Authentic" Science: Results from a University/High School Collaboration Integrating Digital Storytelling and Social Networking. Research in Science Education, 50, 505-528. https://doi.org/10.1007/s11165-018-9699-6

Pasternak, E., Fenichel, R., \& Marshall, A. N. (2017). Tips for Creating a Block Language 
with Blockly. In F. Turbak, J. Gray, C. Kelleher, \& M. Sherman (Eds.), 2017 IEEE Blocks and Beyond Workshop (B\&B) (pp. 21-24). IEEE.

https://doi.org/10.1109/BLOCKS.2017.8120404

Price, D. M., Strodtman, L., Brough, E., Lonn, S., \& Luo, A. (2015). Digital Storytelling: An Innovative Technological Approach to Nursing Education. Nurse Educator, 40, 66-70. https://doi.org/10.1097/NNE.0000000000000094

Psomos, P., \& Kordaki, M. (2018). Digital Storytelling Activities: Direct and Indirect Educational Benefits. In E. Langran, \& J. Borup (Eds.), Society for Information Technology \& Teacher Education International Conference (pp. 316-322). Association for the Advancement of Computing in Education. https://www.learntechlib.org/p/182542/

Ramm, S., Kopf, E. M., Dinter, B., \& Hönigsberg, S. (2021). What Makes a Good Story-The Use and Acceptance of Storytelling in Business Intelligence. In T. X. Bu (Ed.), Hawaii International Conference on System Sciences (HICSS) (pp. 5706-5715). Creative Commons.

Rice, C., LaMarre, A., Changfoot, N., \& Douglas, P. (2018). Making Spaces: Multimedia Storytelling as Reflexive, Creative Praxis. Qualitative Research in Psychology, 17, 222-239.

Rizvic, S., Okanovic, V., \& Boskovic, D. (2020). Digital Storytelling. In F. Liarokapis, A. Voulodimos, N. Doulamis, \& A. Doulamis (Eds.), Visual Computing for Cultural Heritage (pp. 347-367). Cham: Springer.

Robin, B. (2016). The Power of Digital Storytelling to Support Teaching and Learning. Digital Education Review, No. 30, 17-29.

Robin, B. R., \& McNeil, S. G. (2019). Digital Storytelling. In P. Mihailidis, \& R. Hobbs (Eds.), The International Encyclopedia of Media Literacy (pp. 1-8). Wiley-Blackwell.

Sintonen, S. (2020). From an Experimental Paper to a Playful Screen: How the Essence of Materiality Modulates the Process of Creation. British Journal of Educational Technology, 51, 1322-1333.

Whyte, R., Ainsworth, S., \& Medwell, J. (2020). Designing Multimodal Composition Activities for Integrated k-5 Programming and Storytelling. In M. Gresalfi, \& I. S. Horn (Eds.), The Interdisciplinarity of the Learning Sciences, 14th International Conference of the Learning Sciences (ICLS) 2020 (pp. 1317-1324). International Society of the Learning Sciences.

Wood, A. (2007). Digital Encounters. New York: Routledge. https://doi.org/10.4324/9780203825877

Wu, J., \& Chen, D. T. V. (2020). A Systematic Review of Educational Digital Storytelling. Computers \& Education, 147, Article ID: 103786. https://doi.org/10.1016/j.compedu.2019.103786

Yang, Y. T. C., Chen, Y. C., \& Hung, H. T. (2020). Digital Storytelling as an Interdisciplinary Project to Improve Students' English Speaking and Creative Thinking. Computer Assisted Language Learning, 2020, 1-23. https://doi.org/10.1080/09588221.2020.1750431

Yiğit, E. Ö. (2020). Digital Storytelling Experiences of Social Studies Pre-Service Teachers. International Journal of Technology in Education, 3, 70-81. https://files.eric.ed.gov/fulltext/EJ1264134.pdf

Zhang, N., \& Biswas, G. (2017). Defining and Assessing Students' Computational Thinking. In S. C. Kong, \& H. Abelson (Eds.), Computational Thinking Education (pp. 203-221). Singapore: Springer. https://doi.org/10.1007/978-981-13-6528-7 12 